\title{
TINGKAT KEPUASAN WISATAWAN TERHADAP KUALITAS PELAYANAN SHUTTLE BUS KOMOTRA BALI DI CENTRAL PARK KUTA
}

\author{
I Wayan Suardana \\ I Ketut Suwena \\ Luh Gede Leli Kusuma Dewi \\ Email : suar_dana91@yahoo.com \\ PS. S1 Industri Perjalanan Wisata \\ Fakutas Pariwisata UNUD
}

\begin{abstract}
This research discus tourists satisfaction hwo using service of Shuttle Bus Komotra Bali. Shuttle Bus Komotra Bali is one of transportation located at Kuta area. This study aims to determine tourist satisfaction knowing what factors are important and need to be maintained to achieve the satisfaction of tourist. The data collection method in this study conducted by observation, interviews, and questioner. Types of data used is the qualitative quantitative data, whereas the data source is primary and secondary data. Technique of determining the sample using the quota sampling. Data analysis techniques using performance-level analysis and interests (Importance-Performance Analysis). From the results of research, it can be concluded that in general, tourists feel dissatisfactory with the performance or quality of services provided by the Shuttle Bus Komotra Bali with an average compliance rate of 72,22 percent of the respondents. The indicators are considered important and should be maintained to to increase satisfaction performance among other Transportation's condition (2), ready to help with good of quality service and hospitality (5), trust to drivers (10).

Based on the results of discussion, recommended to the Shuttle Bus Komotra Bali to maintain and even improve the performance or quality of service to the factor considered important bay tourist, so as to provide optimum satisfaction to the tourist, which in turn can be used as advantages by Shuttle Bus Komotra Bali compete with another transfrtation.
\end{abstract}

Keywords: Analysis, Quality and Tourist Satisfaction.

\section{PENDAHULUAN}

Kegiatan pariwisata berkembang secara pesat di seluruh dunia termasuk Indonesia yang mengandalkan sektor pariwisata sebagai salah satu pendapatan Negara selain hasil bumi, gas, minyak, dan pertambangan yang dimiliki. Provinsi yang paling banyak di kunjungi wisatawan lokal maupun mancanegara adalah Bali. Perkembangan pariwisata di Bali, amatlah pesat, dimana seperti telah kita ketahui bahwa Bali merupakan salah satu destinasi pariwisata andalan di Indonesia yang juga merupakan salah satu ikon pariwisata di dunia. Bali memiliki banyak tempat yang menarik untuk dikunjungi dan keberadaannya mudah untuk dicapai wisatawan. Berbagai daya tarik wisata dan potensi wisata yang menarik dimiliki oleh Bali, seperti seni, tradisi, keindahan alam, 
budaya serta keramah-tamahanan masyarakat, yang menjadikan Bali sebagai salah satu daerah tujuan wisata utama bagi wisatawan Dunia.

Kabupaten Badung menjadi salah satu kabupaten yang paling banyak dikunjungi wisatawan domistik maupun mancanegara. Ini dikarenakan mayoritas destinasi wisata terkenal tersebar di daerah Kuta, Jimbaran, Nusa Dua, Tuban yang berada di wilayah Kabupaten Badung, maka tidak heran apabila Kabupaten Badung menjadi kabupaten terkaya di Bali. Sebagai Kabupaten yang memiliki daerah tujuan wisata dan kunjungan wisatawan terbanyak, tidak berarti Kabupaten Badung terlepas dari kendala atau hambatan bagi perkembangan pariwisatanya. Salah satu kendala yang dialami adalah kemacetan yang sebagian besar terjadi di daerah Kuta, yang dikarenakan akses yang masih minim atau sempit, dan banyaknya proyek pembangunan. Seiring dengan kemajuan pariwisata di Kuta, menyebabkan kebutuhan terhadap sarana transportasi semkin meningkat. Hal ini yang menyebabkan terjadinya kemacetan di daerah Kuta. Pemerintah dan masyarakat Bali berwanti-wanti untuk meminimalis kemacetan yang terjadi, dengan cara pelebaran jalan di daerah-daerah yang dianggap sering mengalami kemacetan. Tidak hanya itu saja, pemarintah juga mengeluarkan kebijakan yaitu sarana transportasi alternatif yang dianggap mampu meminimalis kemacetan tersebut, yang di tempatkan di Central Park Kuta. Dengan adanya sarana transportasi ini wisatawan yang akan berwisata ke daerah Kuta menggunakan bus pariwisata, terlbih dahulu transit di Central Park Kuta yang kemudian diangkut dengan sarana transportasi ini yang dinamai Shuttle Bus Komotra Bali.

Shuttle Bus Komotra Bali merupakan Salah satu sarana transportasi alternatif yang terdapat di daerah kuta, yang diharapkan mampu meminimalisir kemacetan yang terus terjadi. Transportasi ini bernaung dibawah Koprasi Komotra
Bali, yang dimana dari nama koprasi inilah kemudian menjadi Shuttle Bus Komotra Bali. Transportasi ini bertempat di Central Park Kuta, pangsa pasar yang dituju adalah wisatawan domistik, namun terkadang ada juga wisatawan mancanegara yang menggunakan jasa transportasi ini. Trayek resminya meliputi : Kuta, Tuban, Legian dan Seminyak, namun tidak jarang digunakan untuk keluar kawasan Kuta, seperti : Tabanan, Karangasem dan sebagainya. Adapun pokok permasalahan yang diangkat dalam peneitian ini adalah bagaimanakah tingkat kepuasan wisatawan terhadap kualitas pelayanan Shuttle Bus Komotra Bali serta faktor-faktor pennting yang perlu diperhatikan untuk mencapai tingkat kepuasa wisatawan.

\section{TINJAUAN PUSTAKA}

Dalam dunia pariwisata, transportasi memiliki peran yang sangat penting dalam usaha mengembangkan kepariwisataan. Transportasi selain sebagai sarana bagi masyarakat dalam melakukan aktifitas prekonomian, juga merupakan alat atau sarana bagi wisatawan untuk menuju ke suatu daerah tujuan wisata. Selain itu, dengan adanya transportasi yang baik akan membuka daerah-daerah yang potensial untuk dikembangkan menjadi daerah tujuan wisata.

Yoeti (1999 : 34) memberikan batasan bahwa "Wisatawan adalah seseorang yang melakukan perjalanan untuk sementara waktu, tidak kurang selama 24 jam, dan ia semata-mata sebagai konsumen, bukan pencari nafkah atau bekerja di tempat yang ia kunjungi”.

Oliver, (dalam J. Supranto 2006 : 233), memaparkan kepuasan adalah tingkat perasaan seseorang setelah membandingkan kinerja/hasil yang dirasakannya dengan harapannya.

Untuk mencapai tingkat kepuasan wisatawan pihak manajemen Shuttle Bus Komotra Bali harus lebih meningkatkan dan teliti dalam memberikan pelayanan kepada wisatawan. 
Dalam persaingan di dunia bisnis, agar lebih unggul dari pesaingnya perusahaan memiliki cara tersendiri yaitu dengan memberikan pelayanan yang lebih berkualitas kepada para pelanggannya. Harapan pelanggan berawal dari masa lalu, mendengar dari cerita teman serta promosi dari perusahaan, seklanjutnya dibandingkannya ( J. Supranto, 2006 : 230).

\section{METODE PENELITIAN}

Lokasi penelitian dilakukan di Central Park Kuta, di areal Jalan Raya Kuta, Kelurahan Kuta, Kabupaten Badung, Bali. Sumber data yang digunakan adalah data primer dan data sekunder. Teknik pengambilan sampelnya dilakukan dengan cara accidental sampling. Teknik analisis data yang digunakan dalam penelitian ini adalah : Analisis kuantitatif, penelitian ini menggunakan metode analisis ImportacePerformance Analysis (John A. Martila and John C. James dalam Supranto, 2006 : 239) atau lebih dikenal dengan analisis Tingkat Kepentingan dan Kepuasan Pelanggan. Dalam penelitian ini menggunakan skala sikap responden (Skala Likert). Dalam analisis data menggunakan adalah analisis kualitatif dan kualitatif.

\section{HASIL DAN PEMBAHASAN Karakteristik Wisatawan}

Berdasarkan jenis kelamin wisatawan yang menggunakan Shuttle Bus Komotra Bali kebanyakan oleh laki-laki. Berdasarkan asal kebanyakan wisatawan dari jakarta, karena wisatawan dari jakarta memiliki motivasi lebih untuk berwisata.

Sementara untuk karakteristik berdasarkan frekuensi menggunakan transportasi Shutle Bus Komotra Bali oleh wisatawan adalah sering, karena sarana transportasi ini dapat mengantarkan wisatawan sampai ke pantai Kuta dengan lancar. Dan terakhir untuk karakteristik berdasarkan umur wisatawan yang menggunakan transportasi ini kebanyakan umur 15-20 tahun (pelajar).

\section{Analisis Variabel Indikator Bukti Langsung (Tangibles)}

Dari 50 responden untuk indikator kebersihan dan kerapian kendaraan saat digunakan diperoleh tingkat kesesuain sebesar 83,08 persen, untuk nilai kinerja 4,34 dan nilai kepentingan 4,02. Untuk indikator kondisi kendaraan yang digunakan diperoleh tingkat kesesuaian 75,33 persen, untuk nilai kinerja 3,42 dan untuk nilai kepentingan 4,54. Berikutnya yaitu penampilan dan kerapian pengendara Shutle Bus Komotra Bali memproleh tingkat kesesuaian 71,13 persen, untuk nilai kinerja 2,76 dan untuk nilai kepentingan 3,88 .

\section{Analisis Variabel Indikator Keandalan (Realibity)}

Dari indikator ketepatan waktu dalam penjemputan penumpang memproleh tingkat kesesuain sebesar 81,28 persen, untuk nilai kinerja 3,3 dan untuk nilai kepentingan 4,06. Untuk indikator pelayanan yang ramah serta selalu siap menolong memproleh tingkat kesesuaian sebesar 77,56 persen, 3,18 untuk nilai kinerja dan 4,1 untuk nilai kepentingan. Indikator tarif yang dikenakan dalan perjalanan memproleh tingkat kesesuaian sebesar 88,38 persen, 3,5 untuk nilai kinerja dan 3,95 untuk nilai kepentingan.

\section{Analisis Variabel Indikator Daya Tangkap (Responsiveness) \\ Pada indikator kecakapan} pengendara dalam memberikan informasi secara jelas mendapat tingkat kesesuain 61 persen, 2,44 untuk kinerja dan 4 untuk kepentingan. Indikator kemampuan Untuk cepat tanggap dalam menghadapi masalah yang timbul mendapat tingkat kesesuaian 67,6 persen, 2,88 untuk kinerja dan 4,26 untuk kepentingan. Indikator mengerti dengan cepat apa yang diinginkan dan dikeluhkan wisatawan memproleh tingkat kesesuaian 71,21 persen, 2,29 untuk kinerja dan 4,1 untuk kepentingan. 


\section{Analisis Variabel Indikator Jaminan (Assurance)}

Untuk indikator kepercayaan terhadap pengendara memproleh tingkat kesesuain 67,1 persen, 3,06 untuk kinerja dan 4,56 untuk kepentingan. Indikator rasa aman dan nyaman yang diberikan pengendara saat dalam kendaraan memproleh tingkat kesesuaian 62,96 persen, 2,72 untuk kinerja dan 4,32 untuk kepentingan. Indikator jaminan keselamatan yang diberikan kepada penumpang diperoleh tingkat kesesuaian sebesar 68,26 persen, 2,84 untuk kinerja dan 4,16 untuk kepentingan.

\section{Analisis Variabel Indikator Empati (Empaty)}

Sementara itu untuk indikator kesopanan pengendara dalam berkomunikasi dengan penumpang memproleh tingkat kesesuaian 78 persen, 3,12 untuk kinerja dan 4 untuk kepentingan. Indikator kemudahan wisatawan dalam melakukan hubungan baik dengan pengendara memproleh tingkat kesesuaian 68,84 persen, 2,54 untuk kinerja dan 3,8 untuk kepentingan. Indikator berikutnya yaitu kemampuan dalam memberikan perhatian secara khusus kepada wisatawan diperoleh tingkat kesesuaian sebesar 63,68 persen, 2,28 untuk kinerja dan 3,58 untuk kepentingan.

\section{Tingkat Kepuasan Wisatawan}

Dilihat dari hasil perhitungan skor tingkat kesesuaian, total indikator dari variabel tingkat kepuasan memperoleh nilai 72,22 persen, sehingga wisatawan yang menggunakan Shuttle Bus Komotra Bali dikategorikan merasa cukup puas. Pada diagram kartesius terdapat beberapa indikator yang berada pada kuadran A yaitu : Kemampuan untuk cepat tanggap dalam menghadapi masalah yang timbul, mengerti dengan cepat apa yang diinginkan dan dikeluhkan oleh wisatawan, rasa aman dan nyaman yang diberikan pengendara saat di dalam kendaraan, serta jaminan keselamatan yang diberikan kepada penumpang. Kuadran B terdapat indikator kondisi kendaraan saat digunakan dalam perjalanan, pelayanan yang ramah serta selalu siap menolong, dan kepercayaan terhadap pengendara. Pada Kuadran C, indikator penampilan dan kerapian pengendara Shuttle Bus, kecakapan pengendara dalam memberikan informasi secara jelas, kemudahan wisatawan dalam melakukan hubungan dengan pengendara, serta memberikan perhatian secara individu kepada penumpang. Sedangkan pada Kuadran $\mathrm{D}$, indikator kebersihan dan kerapian kendaraan saat digunakan, ketepatan waktu dalam penjemputan penumpang, tarif yang dikenakan dalam perjalanan, dan kesopanan pengendara dalam berkomunikasi dengan penumpang.

\section{SIMPULAN DAN SARAN Simpulan}

Berdasarkan hasil pembahasan di atas, dapat di simpulkan bahwa dari 50 wisatawan yang dijadikan sebagai responden dengan menggunakan 15 indikator pelayanan memperoleh tingkat kesesuaian sebesar 72,22 persen, secara umum wisatawan merasa cukup puas atas pelayanan yang diberikan oleh Shuttle Bus Komotra Bali.

\section{Saran}

Pihak Manajemen Shuttle Bus Komotra Bali disarankan lebih meningkatkan kemampuan untuk cepat tanggap dalam menghadapi masalah yang timbul, mengerti dengan cepat apa yang diinginkan dan dikeluhkan oleh wisatawan, rasa aman dan nyaman yang diberikan pengendara saat di dalam kendaraan, jaminan keselamatan yang diberikan kepada penumpang. Indikatorindikator tersebut merupakan indikator yang dianggap penting oleh wisatawan namun kinerjanya belum memuaskan.

\section{DAFTAR PUSTAKA}

Kotler, Philip.2000. Manajemen Pemasaran. Jakarta : Prenhanllindo. 
Vol. 1 No. 1, 2013

Supranto, Johanes. 2006. Pengukuran Tingkat Kepuasan Pelanggan Untuk Menaikkan Pangsa Pasar. Jakarta : Rineka Cipta.

Negara, Suta I Kadek. 2010. "Persepsi Penumpang Terhadap Kualitas
Pelayanan Pengendara MotorTaxi pada PT. Indonesia MotorTaxi Corp di Denpasar". (Sebuah Laporan Akhir) Universitas Udayana. Denpasar.

Yoeti, Oka A. 1993. Pengantar Ilmu Pariwisata. Bandung : Angkasa. 